\title{
Rapid Oxidation Characterization of Ultra-High Temperature Ceramics
}

\author{
Sigrun N. Karlsdottir ${ }^{\dagger}$ and John W. Halloran \\ Materials Science and Engineering Department, University of Michigan, Ann Arbor, Michigan 48109-2136
}

\begin{abstract}
Here, a novel method for testing ultra-high-temperature ceramics (UHTC) at a high temperature, rapidly, at a low cost is introduced. A self-supported, self-heated ribbon specimen is used with a table-top apparatus to achieve the necessary high temperatures. This method enables a large temperature-time-composition parameter space to be covered by rapidly producing a large set of postoxidation samples for analysis. The complex oxide scale known to form during oxidation of UHTC materials is shown to be easily reproduced using this method. $\mathrm{A} \mathrm{ZrB}_{2}-\mathrm{SiC}$ (15 vol\%) UHTC material was tested at $1700^{\circ} \mathrm{C}$ for $15 \mathrm{~min}$. The oxide scale consists of a thin outermost silica $\left(\mathrm{SiO}_{2}\right)$ layer and a zirconia $\left(\mathrm{ZrO}_{2}\right)$ columnar layer with small amounts of $\mathrm{SiO}_{2}$ embedded between the $\mathrm{ZrO}_{2}$ columns. A region of $\mathrm{SiC}$ depleted zone was observed between the unreacted core and the $\mathrm{ZrO}_{2}$ layer. The measured thickness of the oxide scale was 102 $\mu \mathrm{m}$ and $\sim 120 \mu \mathrm{m}$ for the SiC-depleted zone.
\end{abstract}

\section{Introduction}

$\mathrm{R}$ ECENTLY, interest in ultra-high temperature ceramics (UHTC) has increased significantly due to the drive to produce a reusable thermal protection system and other components for future generations of hypersonic aerospace vehicles. ${ }^{1}$ Most modern designs of hypersonic vehicles incorporate sharp aero-surfaces to increase aerodynamic performance. These designs require materials capable of operating in an extreme reentering environment, such as an oxidizing atmosphere at temperatures above $1700^{\circ} \mathrm{C}$ and corrosive gases at high velocities. ${ }^{2}$ Today, there are few fully developed materials that meet the needs of thermal protection systems for sharp aero-surfaces and so UHTC are receiving more attention as the solution.

UHTC are a class of refractory materials including transition metal borides, carbides, and nitrides. The refractory borides, i.e. $\mathrm{ZrB}_{2}$ and $\mathrm{HfB}_{2}$, have extremely high melting temperatures, $>3000^{\circ} \mathrm{C}$, high thermal conductivity, high hardness, and retained strength and chemical stability at elevated temperatures. ${ }^{3}$ As early as $1953, \mathrm{ZrB}_{2}$ - and $\mathrm{HfB}_{2}$-based composites were identified by Hoffman, ${ }^{4}$ followed by groups led by Berkowitz-Mattuck $^{5}$ and Kaufman et al., ${ }^{6}$ as the most promising material for hypersonic applications. In the 1970 s, Kaufman et al. ${ }^{7,8}$ showed that by addition of $\mathrm{SiC}$ to $\mathrm{ZrB}_{2}$ and $\mathrm{HfB}_{2}$, the oxidation resistance could be greatly improved. Tripp 9 and Tripp and Graham $^{10}$ confirmed Kaufman's results and provided additional information such as microstructural studies of the oxide scale. Past studies by Levine et al., ${ }^{11}$ Nguyen et al., ${ }^{12}$ Opila et al. ${ }^{13}$ Monteverde et al., ${ }^{14-18}$ Scatteia et al., ${ }^{19}$ Monteverde and Bellosi, ${ }^{20}$ Fahrenholtz Hilmas and colleagues, ${ }^{21,22}$ and others ${ }^{23,24}$ have also shown that addition of $\mathrm{SiC}$ to $\mathrm{ZrB}_{2}$ and $\mathrm{HfB}_{2}$ increases densification, thermal shock, and oxidation resistance of the

D. Butt - contributing editor

Manuscript No. 22585. Received December 14, 2006; approved May 3, 2007

This work was financially supported by the Office of Naval Research under the grant $\mathrm{N}$ 0014-02-1-0034.

Presented at the 108th Annual Meeting of The American Ceramic Society (part of the MS\&T '06 Materials Science \& Technology Conference and Exposition), Cincinnati, OH, 2006.

Author to whom correspondence should be addressed. e-mail: nanna@umich.edu composites. These researchers have discovered that $\mathrm{ZrB}_{2}-\mathrm{SiC}$ and $\mathrm{HfB}_{2}-\mathrm{SiC}$ composites form a complex oxide scale after oxidation at elevated temperatures. The oxide scale is composed of refractory oxide skeleton and amorphous glass components that provide oxidation resistance of the composites at high temperatures.

Despite the fact that it has been almost 50 years since researchers started to explore UHTC materials the oxidation mechanisms of these materials are still not well understood. This is primarily due to the complexity of the oxide scale and limited information. Also, much of the oxidation experiments that have been conducted were at temperatures below $1700^{\circ} \mathrm{C}$. The main exception is NASA's Arc Jet Facility used to simulate aerodynamic heating. It is capable of reaching temperatures from $1700^{\circ}$ to $2500^{\circ} \mathrm{C} .^{1,21,25,13}$ Arc jet testing is expensive due to the high power used during testing (40-75 MW), and the facilities are operated primarily to support the government aerospace research and developmental testing. ${ }^{25}$ Nongovernmental groups can apply for its use, but it is both time consuming and complicated. ${ }^{26}$

Here, we report a novel method for testing UHTC materials at high temperatures rapidly at low cost. A self-supported, selfheated ribbon specimen is used with a table-top apparatus to achieve the necessary high temperatures for UHTC oxidation experiments. The present work introduces the design of the system and function. Also, the complex oxide scale that forms during oxidation of UHTC is shown here to be easily reproduced using the ribbon method.

\section{The Ribbon Method}

\section{(1) The Self-Supported Ribbon Specimen}

The design of the table-top apparatus is based on the fact that the UHTC materials are metallic conductors. A miniaturized self-supportive UHTC specimen is resistively heated by passing a modest current. The specimen is fabricated by reducing the thickness of a matchstick-size sample in the center to make a ribbon with a thickness of $400-500 \mu \mathrm{m}$. The ribbon, herein called the hot zone, can reach very high temperatures when the current is passed into the thicker ends of the specimen. The thicker ends of the specimen will remain relatively cool, while the hot zone can reach the desired temperature. With this geometry the specimen is self-supportive (Fig. 1). The hot zone is thus not in contact with foreign material. This is important, because at these high temperatures, the specimen may react with the materials it contacts. The specimen is in open air during testing, and it has a small heat load, and so diagnostics can be brought close to it during oxidation.

\section{(2) The Table-Top Apparatus}

A table-top apparatus provides the current and controls the temperature of the specimen. The control unit of the apparatus consists of a control panel (MHI BPAN-O ${ }^{\mathrm{TM}}$, Micropyretics Heaters Int., Cincinnati, $\mathrm{OH})$, and a programmable temperature controller (Model 2416, Eurotherm, Leesburg, VA). The power controller is a single-phase silicon ( $\mathrm{Si}$ )-controlled rectifier (SCR) with an advanced current limit and a soft start feature. A stepdown transformer is a part of the apparatus and is connected to the controller to give the desired secondary current in the 


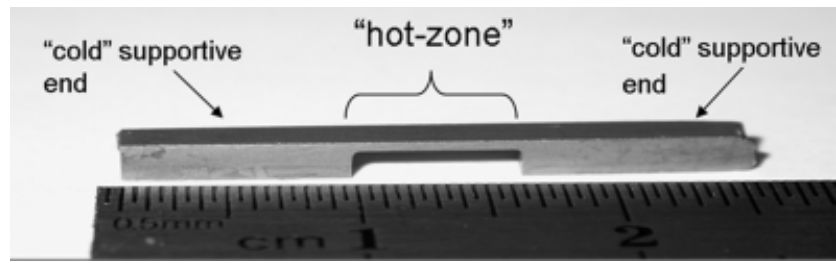

Fig. 1. Digital image of the self-supported, self-heated ribbon specimen.

range of $0-125 \mathrm{~A}$. The power input used to heat the ribbon specimen to temperatures from $900^{\circ}$ to $2000^{\circ} \mathrm{C}$ is around $90-125$ $\mathrm{W}$, where the voltage across the specimen is on the order of $1 \mathrm{~V}$ and the current ranges from 90 to $125 \mathrm{~A}$.

The temperature sensor of the apparatus is a micro optical infrared pyrometer that can measure temperature from $900^{\circ}$ to $3300^{\circ} \mathrm{C}$ with a fast response time (minimum $1 \mathrm{~ms}$ ). The micro pyrometer is a single-color pyrometer with a wavelength of $1 \mu \mathrm{m}$ and a bandwidth of $0.7-1.1 \mu \mathrm{m}$. The micro pyrometer is focused on the hot zone of the specimen and provides the temperature signal to the temperature controller. The amount of current passed through the sample is controlled with the power controller to obtain the desired temperature-time schedule. The UHTC specimen can be quickly heated and cooled due to the fast response of the temperature controller and the pyrometer and the size of the miniaturized sample. Any time-temperature profile, cyclic, or static oxidation can be conducted using the pyrometer signal as the control variable. With the table-top apparatus and the ribbon specimen, oxidation experiments at temperatures in the range of $900^{\circ}-2000^{\circ} \mathrm{C}$ can be performed, without creating a difficult-to-manage heat load in the surroundings due to the small size of the specimen. A similar approach was used by Cabrera and Kirner $^{27}$ for the design of a cyclic metal-oxidation apparatus. Cabrera and Kirner ${ }^{27}$ resistively heated thin Si-coated steel foils, $50-\mu \mathrm{m}$ thick, but these were only capable of reaching temperatures in the range of $400^{\circ}-1000^{\circ} \mathrm{C}$.

Figure 2(a) shows the self-supported miniaturized specimen connected to the table-top apparatus. Figure 2(b) shows the specimen sitting on a simple (copper) $\mathrm{Cu} /($ silver) $\mathrm{Ag}$ bridge fixed with alligator clips, which can serve as voltage probes. The bridge consists of $\mathrm{Cu}$ plates that hold up $\mathrm{Ag}$ sheets where the thicker ends of the specimen sit. The $\mathrm{Cu}$ plates are connected to the current leads and fixed to a thermal insulation base plate (Transite ${ }^{(B)}$ HT, Monaco, MI). Ag was used for connecting the specimen to the $\mathrm{Cu}$ plates due to its high conductivity and oxidation resistance ( $\mathrm{Cu}$ was not suitable due to its poor oxidation resistance). Thin alumina $\left(\mathrm{Al}_{2} \mathrm{O}_{3}\right)$ sheets were used between the alligator clips and the sample as heat shields, to avoid over heating of the alligator clips.

Temperature, current, and voltage are recorded by a LabView DAQ. An AC clamp on adapter is clamped on the secondary wire in the circuit to detect the current going through the specimen, and then transfers it to a data acquisition card (DAQ) (NI USB-6009, National Instruments Corporation, Austin, TX) connected to a computer. The temperature measured with the micro pyrometer is transferred to the computer through a RS-232 cable. To process the data from the DAQ and the RS-232 cable, LabVIEW from National Instruments is used. A LabVIEW program was designed to collect and save the temperature, current, and voltage data sampled during testing. The LabVIEW program samples the signal from the DAQ and the RS-232 cable (connected to the pyrometer) and plots the RMS current versus time and the temperature versus time. The data are collected at a sampling frequency of $4 \mathrm{~Hz}$, i.e. the sampling time is $250 \mathrm{~ms}$. Figure 3 shows an example of a temperature and a current profile of a ribbon specimen tested in the apparatus at $1600^{\circ} \mathrm{C}$ for $15 \mathrm{~min}$.

\section{Experimental Procedure}

\section{(1) Material Fabrication}

The UHTC material, $\mathrm{ZrB}_{2}-15 \mathrm{vol} \% \mathrm{SiC}$, used in this work was provided by The Institute of Science and Technology for Ceramics (CNR-ISTEC) in Faenza, Italy. Details of the properties and processing are presented in more detail elsewhere. ${ }^{28}$ The fabrication of the self-supporting specimens is performed in two steps. Firstly, the bulk material is cut with a wire-EDM machine

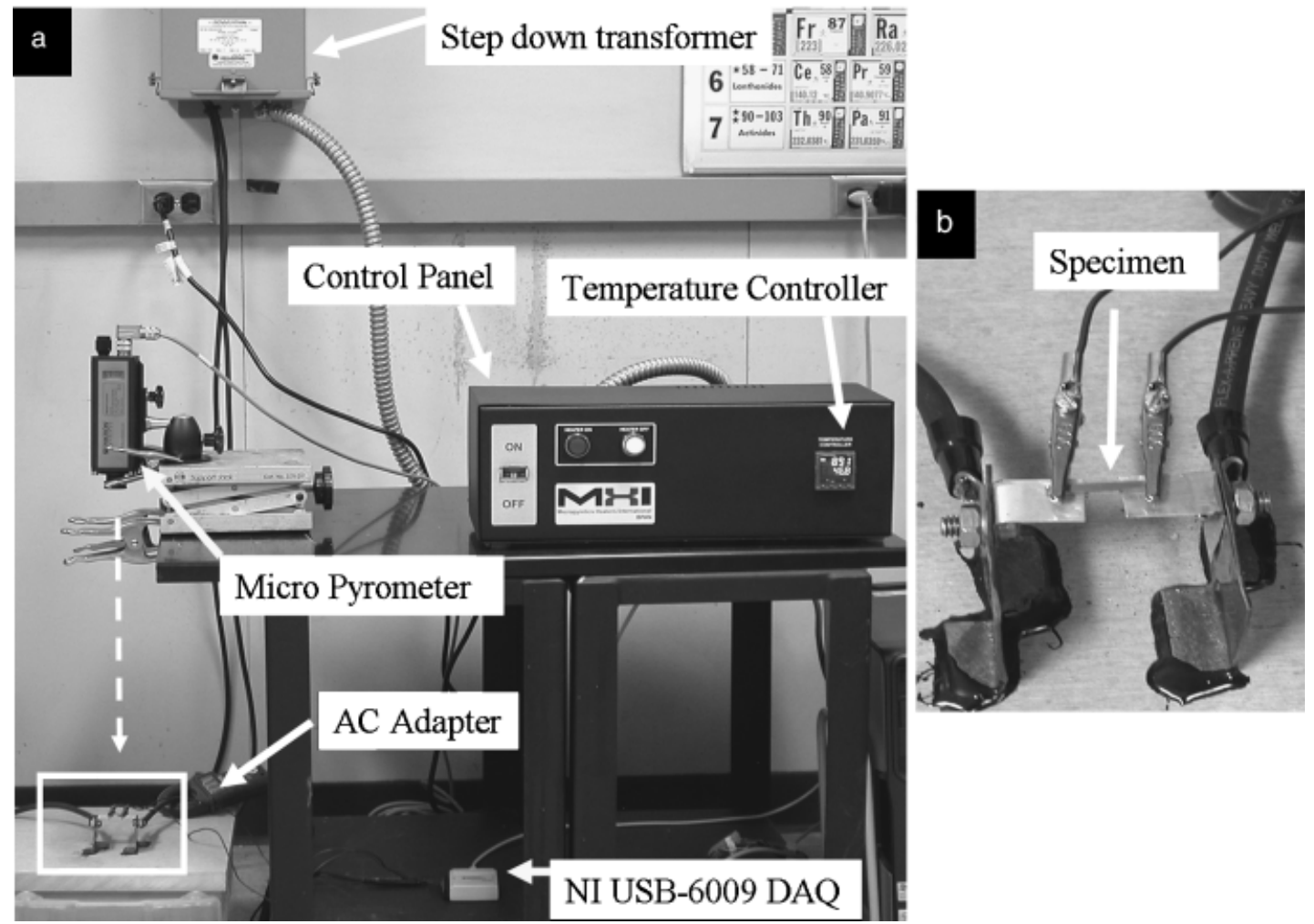

Fig. 2. (a) The self-supported ribbon specimen (white box) and its table-top apparatus, (b) the specimen sitting on a copper (Cu)/silver (Ag) holder (magnification of the white box in the lower left corner of (a)). 

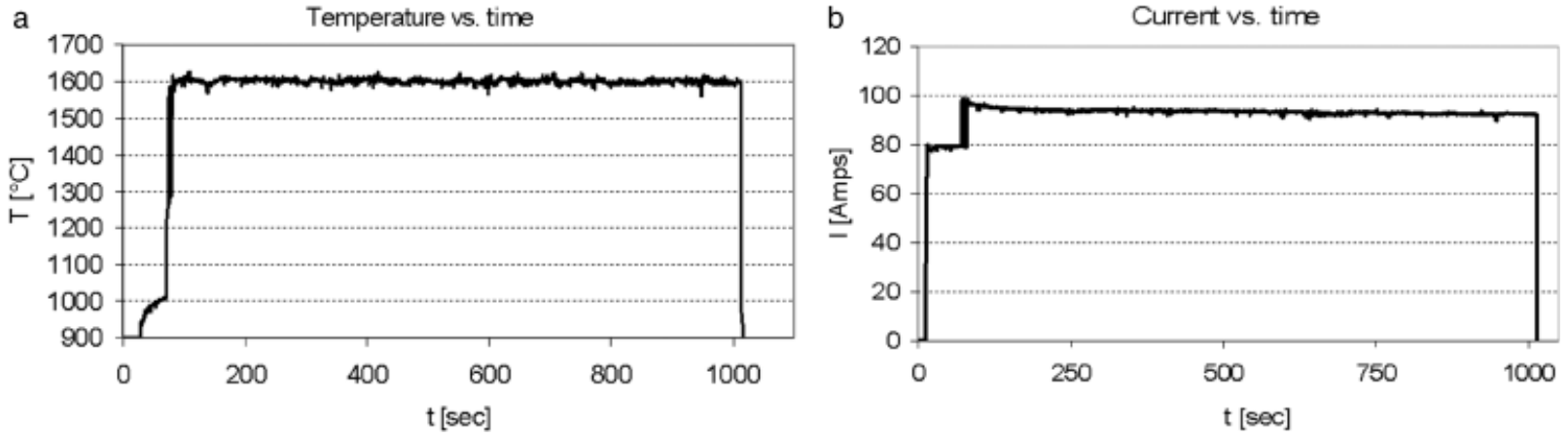

Fig. 3. (a) Temperature profile, (b) and a current profile of a specimen tested at $1600^{\circ} \mathrm{C}$ for $15 \mathrm{~min}$.

into $2.3 \mathrm{~mm} \times 2.0 \mathrm{~mm} \times 25 \mathrm{~mm}$ bars. The bars are then reduced in thickness in the center with a mechanical grinder (220 gritdiamond wheel) to make the thin ribbon hot zones, with a thickness of 400-500 $\mu \mathrm{m}$; see Fig. 1 .

\section{(2) Oxidation Testing}

To verify whether the ribbon specimen method could reproduce the complex oxide scales that form during high-temperature experiments on $\mathrm{UHTC}, \mathrm{ZrB}_{2}-\mathrm{SiC}$ specimens (CNR-ISTEC, Italy) were tested in the high-temperature apparatus. The specimen was tested at $1700^{\circ} \mathrm{C}$ in stagnant ambient air for $15 \mathrm{~min}$, at a heating rate of $480^{\circ} \mathrm{C} / \mathrm{min}$ and free cooling $\left(767^{\circ} \mathrm{C} / \mathrm{s}\right)$. The fast cooling rate is due to the fast thermal response time $(2.98 \mathrm{~ms}$ at $1700^{\circ} \mathrm{C}$ ) of the specimen, which is dependent on the thickness of the specimen $(t=420 \mu \mathrm{m})$ and its thermal diffusivity $\left(1.41 \times 10^{-5} \mathrm{~m}^{2} / \mathrm{s}\right.$ at $\left.1700^{\circ} \mathrm{C}\right)$. The fast heating minimizes the oxidation before the isothermal run at $1700^{\circ} \mathrm{C}$.

The tested specimen was stored in moisture-free desiccators. A cross section of the oxidized specimen was prepared for microstructural analysis by nonaqueous polishing procedures down to a $1 \mu \mathrm{m}$ finish. The composition and morphology of the multilayer oxide scale formed after the oxidation test were characterized by scanning electron microscopy (SEM; Philips XL30, Hillsboro, OR), backscattering electron microscopy (BSE; Philips), X-ray energy dispersive spectroscopy (XEDS; UTW Si-Li Solid State X-ray Detector with integrated EDAX Phoenix XEDS system, Mahwah, NJ), and electron microprobe analyzer (EPMA; Cameca SX100 Microprobe, Gennevilliers, France). Analyses were performed on the surface of the specimen and cross section.

\section{Results and Discussion}

When monolithic $\mathrm{ZrB}_{2}(s)$ oxidizes an oxide scale composed of zirconia, $\mathrm{ZrO}_{2}(s)$, and boron oxide liquid, $\mathrm{B}_{2} \mathrm{O}_{3}(l)$, forms by the reaction $^{16}$

$$
\mathrm{ZrB}_{2}(s)+5 / 2 \mathrm{O}_{2}(g) \rightarrow \mathrm{ZrO}_{2}(s)+B_{2} \mathrm{O}_{3}(l)
$$

The liquid $\mathrm{B}_{2} \mathrm{O}_{3}$ forms a continuous passive layer acting as a barrier to oxygen $(\mathrm{O})$ diffusion, which results in passive oxidation of $\mathrm{ZrB}_{2}$ and a parabolic oxidation kinetics below ca. $1000^{\circ} \mathrm{C}$. Above $1000^{\circ} \mathrm{C}$, the oxidation resistance of $\mathrm{ZrB}_{2}$ is poor due to volatilization of $\mathrm{B}_{2} \mathrm{O}_{3} .{ }^{21}$ The kinetics is then controlled by the competition between mass gain $\left(\mathrm{ZrO}_{2}(s)\right.$ and $\mathrm{B}_{2} \mathrm{O}_{3}(l)$ formation) and mass loss $\left(\mathrm{B}_{2} \mathrm{O}_{3}(g)\right.$ vaporization). At higher temperatures, $\mathrm{ZrB}_{2}$ actively oxidizes due to volatilization of the $\mathrm{B}_{2} \mathrm{O}_{3}$ liquid, and results in a porous, nonprotective $\mathrm{ZrO}_{2}$ layer. ${ }^{5,16,21-23}$ Researchers have reported that by adding $\mathrm{SiC}$ to $\mathrm{ZrB}_{2}$, the oxidation resistance of the composite above $1200^{\circ} \mathrm{C}$ is improved by the formation of a less volatile silica $\left(\mathrm{SiO}_{2}\right)$-rich glass on the exposed surface ${ }^{1,10,21,11,13,18}$ :

$$
\mathrm{SiC}(\mathrm{s})+3 / 2 \mathrm{O}_{2}(g) \rightarrow \mathrm{SiO}_{2}(s)+\mathrm{CO}(g)
$$

The $\mathrm{SiO}_{2}$-rich layer has been reported to provide passive oxidation resistance to at least $1500^{\circ} \mathrm{C}$ due to the lower volatility of $\mathrm{SiO}_{2}$ compared with $\mathrm{B}_{2} \mathrm{O}_{3}$ at these temperatures.

Figure 4 shows an SEM image of the surface of the tested $\mathrm{ZrB}_{2}-15 \mathrm{vol} \% \mathrm{SiC}$ specimen. The bright peaks shown in Fig. 4(a) indicate $\mathrm{ZrO}_{2}$ peaks embedded in a $\mathrm{SiO}_{2}$-rich glass matrix, verified by XEDS analysis (Fig. 4(b)). A BSE image of the cross section of the specimen (Fig. 5) shows that the oxide

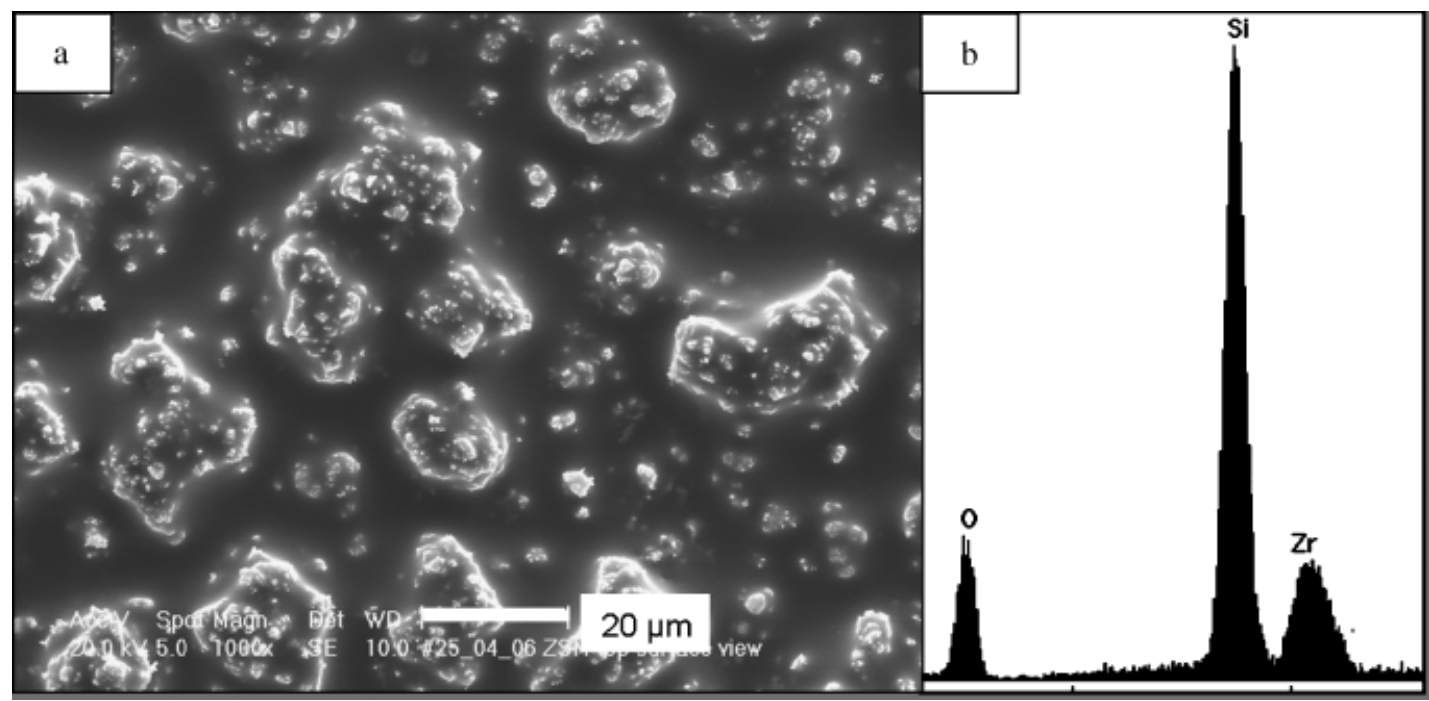

Fig. 4. Surface view of the $\mathrm{ZrB}_{2} / \mathrm{SiC}$ composite tested at $1700^{\circ} \mathrm{C}$ for $15 \mathrm{~min}$, (a) zirconia $\left(\mathrm{ZrO}_{2}\right)$ peaks embedded in a silica $\left.(\mathrm{SiO})_{2}\right)$ glass matrix, (b) X-ray energy dispersive spectroscopy analysis of the surface. 


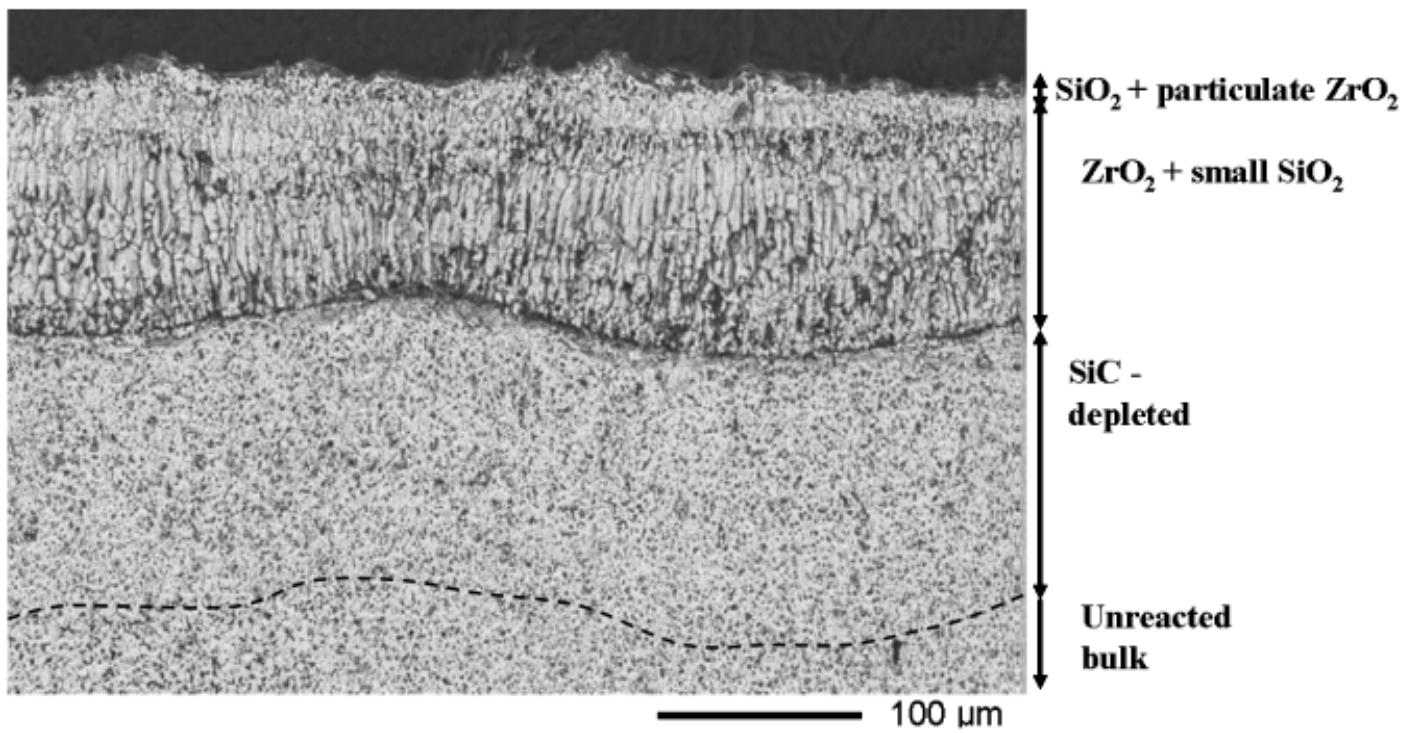

Fig. 5. Image of a cross section of a $\mathrm{ZrB}_{2} / \mathrm{SiC}$ composite tested at $1700^{\circ} \mathrm{C}$ for $15 \mathrm{~min}$. Multilayer oxide scale, consisting of an unaffected substrate, a $\mathrm{SiC}$-depleted zone, a columnar zirconia $\left(\mathrm{ZrO}_{2}\right)$ layer, and a thin superficial layer of silica $\left(\mathrm{SiO}_{2}\right)$ glass.

scale of the specimen is multilayered and multicomponent. The chemical composition of the oxide scale was characterized by XEDS and EPMA techniques. The oxide scale consists of a thin superficial layer of a $\mathrm{SiO}_{2}$ glass containing a small amount of particulate $\mathrm{ZrO}_{2}$; the second layer mainly consists of columnar $\mathrm{ZrO}_{2}$ grains. The columnar $\mathrm{ZrO}_{2}$ layer has a small amount of
$\mathrm{SiO}_{2}$ glass embedded between the $\mathrm{ZrO}_{2}$ columns. The thickness of the oxide scale was measured to be on average $102 \mu \mathrm{m}$. A region of the $\mathrm{SiC}$-depleted zone was observed between the unreacted core and the $\mathrm{ZrO}_{2}$ layer. The SiC-depleted zone is large ca. $120 \mu \mathrm{m}$, which results in a small region of unreacted material (core). This is evident from the elemental maps from the EPMA


Fig. 6. (a) Backscattering electron microscopy (BSE) image of the cross section of the $\mathrm{ZrB}_{2} / \mathrm{SiC}$ specimen tested at $1700^{\circ} \mathrm{C}$ for $15 \mathrm{~min}$, (b) $\mathrm{O}$ map, showing the oxygen distribution in the silica $\left(\mathrm{SiO}_{2}\right)$ and zirconia $\left(\mathrm{ZrO}_{2}\right)$ scales, (c) $\mathrm{Zr}$ map, (d) Si map, showing the large SiC-depleted region and the thin strip of the unreacted core, (e) B map, showing the thickness of the oxide scale and the unreacted $\mathrm{ZrB}_{2}$ in the SiC-depleted zone. The white dashed line in (b-e) outlines the thickness of the specimen. The white color in the maps indicates the higher intensity of X-rays detected for each element, while the black region represents zero detected intensity of the element. 
analysis (Fig. 6). The existence of a $\mathrm{SiC}$-depleted layer in oxidized $\mathrm{ZrB}_{2} / \mathrm{HfB}_{2}-\mathrm{SiC}$ composites has been reported by other researchers in the field. ${ }^{10,17,21,25}$

The EPMA analyses were performed on the cross section shown in the BSE image in Fig. 6(a). The analyses were mainly performed to verify the results from the XEDS on the distribution of the elements: $\mathrm{Si}$, O, zirconium ( $\mathrm{Zr}$ ), and boron (B). Also, $B$ could not be detected with the SEM/XEDS machine used; thus, EPMA analyses were performed to give us information on whether there existed any borosilicate glass or $\mathrm{B}_{2} \mathrm{O}_{3}$ in the oxide scale. $\mathrm{B}_{2} \mathrm{O}_{3}$ was not detected in the $\mathrm{SiO}_{2}$-rich scale or in the $\mathrm{ZrO}_{2}$ columnar region with EPMA; this is likely due to the small amount of $\mathrm{B}_{2} \mathrm{O}_{3}$ existing in the oxide scale, which could not be detected with the scanning speed $(20 \mathrm{~ms})$ used for the EPMA analysis. The small amount of $\mathrm{B}_{2} \mathrm{O}_{3}$ is expected due to the high temperature $\left(1700^{\circ} \mathrm{C}\right)$ that the specimen experienced. $\mathrm{B}_{2} \mathrm{O}_{3}$ is believed to start volatilizing extensively at temperatures above $1200^{\circ} \mathrm{C}$ for a monolithic material. ${ }^{16}$ Also, the outermost layer, the thin $\mathrm{SiO}_{2}$-rich scale, will not have the same effective role in limiting $\mathrm{O}$ diffusion at $1700^{\circ} \mathrm{C}$ as at lower temperatures. The use of $\mathrm{SiO}_{2}$-forming ceramics at high temperatures has been reported to be limited to a maximum of $1725^{\circ} \mathrm{C}$ because of rapid oxidation, potential volatility, scale melting, and scale/substrate reactions of the $\mathrm{SiO}_{2}$ formed. ${ }^{29}$

From the $\mathrm{O}, \mathrm{Zr}$, and $\mathrm{Si}$ maps (Figs. 6(a)-(e)), the small amount of interstitial $\mathrm{SiO}_{2}$ glass in the $\mathrm{ZrO}_{2}$ columnar layer can be easily identified. These maps also show clearly the thin outermost $\mathrm{SiO}_{2}$-rich layer (Figs. 6(b)-(d)). As mentioned above, the $\mathrm{SiO}_{2}$ scale contains small amounts of particulate $\mathrm{ZrO}_{2}$. A higher magnification of the $\mathrm{SiO}_{2}$-rich scale and the particulate $\mathrm{ZrO}_{2}$ is shown in Fig. 7; small peaks of the particulate $\mathrm{ZrO}_{2}$ are clearly evident. These peaks were also observed from the surface of the specimen (Fig. 4(a)). The nature of the particulate $\mathrm{ZrO}_{2}$ peaks and their formation mechanism are discussed elsewhere. ${ }^{30}$

Our results are consistent with the results reported by other researchers in the field. Levine et al. ${ }^{11}$ found that the oxide scale of a $\mathrm{ZrB}_{2}-\mathrm{SiC}\left(20 \mathrm{vol} \%\right.$ ) composite, tested in air at $1927^{\circ} \mathrm{C}$ for ten 10-min cycles, was composed of large $\mathrm{ZrO}_{2}$ grains in a $\mathrm{SiO}_{2}-$ rich glassy phase, where the outermost part of the oxide scale contained less $\mathrm{SiO}_{2}$ glass than the inner most part of the scale. They also found that after oxidation testing in air at $1627^{\circ} \mathrm{C}$ for ten 10-min cycles (total $100 \mathrm{~min}$ ), the oxide scale of the composite was composed of two layers: an outer $\mathrm{SiO}_{2}$ layer and a $\mathrm{ZrO}_{2}+\mathrm{SiO}_{2}$ layer. A porous $\mathrm{SiC}$-depleted layer was also observed beneath the oxide scale. Gasch et al. $^{25}$ performed testing on $\mathrm{HfB}_{2}-\mathrm{SiC}(20 \mathrm{vol} \%$ ) composites in a simulated re-entry environment using the NASA Ames Arc Jet Facility. The specimens were tested at $1690^{\circ} \mathrm{C}$ for two 10 -min cycles. Gash et al..$^{25}$ concluded that, for the two conditions, a passive oxidation of the $\mathrm{SiC}$ plays a role in determining the steady-state surface temperature below $1700^{\circ} \mathrm{C}$. This is consistent with our results; the

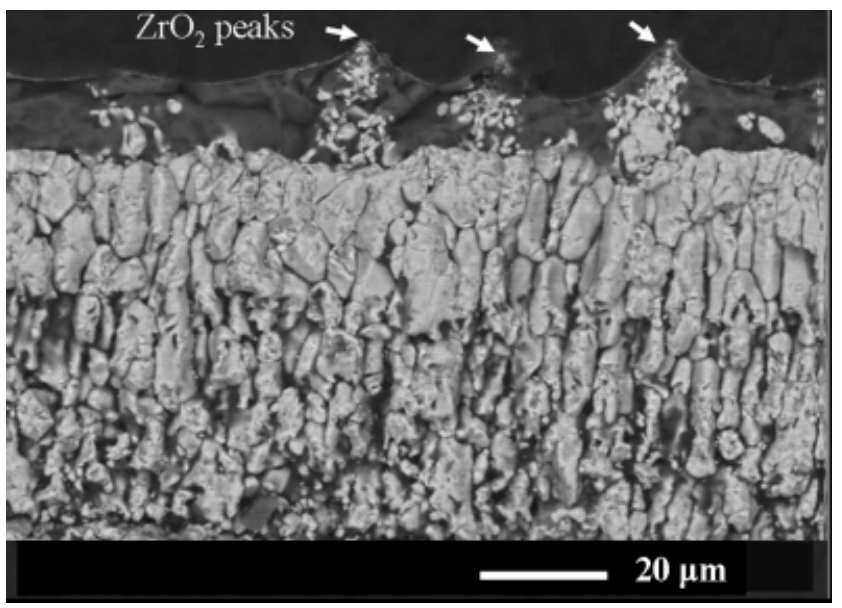

Fig. 7. Backscattering electron microscopy (BSE) image of the silica $\left(\mathrm{SiO}_{2}\right)$ outermost layer containing zirconia $\left(\mathrm{ZrO}_{2}\right)$ particulate peaks. oxide scale of the $\mathrm{ZrB}_{2}-\mathrm{SiC}(15 \mathrm{vol} \%)$ specimen tested at $1700^{\circ} \mathrm{C}$ for 15 min consisted mainly of a $\mathrm{ZrO}_{2}$ columnar layer with a small amount of $\mathrm{SiO}_{2}$ embedded, and a thin outermost $\mathrm{SiO}_{2}$ layer. The large $\mathrm{SiC}$-depleted zone observed for the specimen indicates that the $\mathrm{SiO}_{2}$ layer does not provide enough protection for a passive oxidation at $1700^{\circ} \mathrm{C}$. This is consistent with the prediction by Jacobson ${ }^{29}$ about the limited use of $\mathrm{SiO}_{2}$-forming ceramics at higher temperatures (maximum $1725^{\circ} \mathrm{C}$ ).

\section{Conclusion}

The complex oxide scale known to form during oxidation of UHTC is shown to be easily reproduced by using the ribbon specimen method. The oxide scale of a $\mathrm{ZrB}_{2}-\mathrm{SiC}(15 \mathrm{vol} \%)$ specimen tested at $1700^{\circ} \mathrm{C}$ for 15 min consisted of a thin outermost $\mathrm{SiO}_{2}$ layer and a $\mathrm{ZrO}_{2}$ columnar layer with small amounts of $\mathrm{SiO}_{2}$ embedded between the $\mathrm{ZrO}_{2}$ columns. A region of $\mathrm{SiC}$-depleted zone was observed between the unreacted core and the $\mathrm{ZrO}_{2}$ layer. The measured thickness of the oxide scale was $102 \mu \mathrm{m}$ and the $\sim 120 \mu \mathrm{m}$ for SiC-depleted zone.

The table-top apparatus with its ribbon specimen enables us to perform oxidation experiments at temperatures above $900^{\circ} \mathrm{C}$ and as high as $2000^{\circ} \mathrm{C}$ with power input only around $100 \mathrm{~W}$, without creating a difficult-to-manage heat load in the surroundings due to the small size of the specimen. This new design is a valuable alternative for exposure of UHTC to high temperatures.

\section{Acknowledgments}

The authors would like to thank the following for their contributions in support of this work: Dr. Alida Bellosi and her associates at CNR-ISTEC in Italy for providing the $\mathrm{ZrB}_{2}-\mathrm{SiC}$ material, Carl Henderson for support in EPMA analysis, and Prof. Albert J. Shih and Jia Tao with EDM machining.

\section{References}

${ }^{1}$ M. M. Opeka, I. G. Talmy, and J. A. Zaykoski, "Oxidation-Based Materials Selection for $2000^{\circ} \mathrm{C}+$ Hypersonic Aerosurface: Theoretical Considerations and Historical Experience," J. Mater. Sci., 39 [19] 5887-904 (2004).

${ }^{2}$ P. Kolodziej, "Aerothermal Performance Constraints for Hypervelocity Small Radius Unswept Leading Edges and Nosetips"; NASA Technical Memorandum, 112204, July 1997.

${ }^{3}$ R. Telle, L. S. Sigl, and K. Takagi, "Transition Metal Boride Ceramics"; pp. 803-945 in Handbook of Ceramic Hard Materials, Vol. 2, Edited by R. Reidel. Wiley-VCH, Weinheim, Germany, 2000.

${ }^{4}$ C. A. Hoffman, "Preliminary Investigation of Zirconium Boride Caramels for Gas-Turbine Blade Applicatons"; NASA Technical Memorandum E52L15a, Lewis Flight Propulsion Laboratory, Cleveland, OH, 1953

${ }^{5}$ J. B. Berkowitz-Mattuck, "High-Temperature Oxidation, III. Zirconium and Hafnium Diborides," J. Electrochem. Soc., 113, 908-14 (1966).

${ }^{6}$ L. Kaufman, E. V. Clougherty, and J. B. Berkowitz-Mattuck, "Oxidation Characteristics of Hafnium and Zirconium Diboride," Trans. Metall. Soc. AIME, 239 [4] 458-66 (1967).

${ }^{7}$ L. Kaufman, "Boride Composites-A New Generation of Nose Cap and Leading Edge Materials for Reusable Lifting Reentry Systems," AIAA Advanced Space Transportation Meeting. Am. Inst. Aeronaut. Astronaut., 270-8 (1970).

${ }^{8}$ L. Kaufman and H. Nesor, "Stability Characterization of Refractory Materials under High Velocity Atmospheric Flight Conditions, Part I, Vol. I, Summary"; Technical Report no. AMFL-TR-69-84, Air Force Materials Laboratory, WrightPatterson Air Base, OH, 1970.

${ }^{9}$ W. C. Tripp and H. C. Graham, "Thermogravimetric Study of Oxidation of $\mathrm{ZrB}_{2}$ in Temperature Range of 800 Degrees to 1500 Degrees," J. Electrochem. Soc., 118, 1195-971 (1971).

${ }^{10}$ W. C. Tripp, H. H. Davis, and H. C. Graham, "Effect of SiC Addition on the Oxidation of $\mathrm{ZrB}_{2}, "$ Am. Ceram. Soc. Bull., 52 [8] 612-6 (1973).

${ }^{11}$ S. R. Levine, E. J. Opila, M. C. Halbig, J. D. Kiser, M. Singh, and J. A. Salem, "Evaluation of Ultra-High Temperature Ceramics for Aeropropulsion Use," J. Eur. Ceram. Soc., 22, 2757-67 (2002).

${ }^{12}$ Q. N. Nguyen, E. J. Opila, and R. C. Robinson, "Oxidation of Ultrahigh Temperature Ceramics in Water Vapor," J. Electrochem. Soc., 151 [10] B558-62 (2004)

${ }^{13}$ E. J. Opila, S. R. Levine, and J. Lorincz, "Oxidation of $\mathrm{ZrB}_{2}$ - and $\mathrm{HfB}_{2}$ Based Ultra-High Temperature Ceramics: Effect of Ta Additions," J. Mater. Sci., 39, 5969-77 (2004). 
${ }^{14}$ F. Monteverde, A. Bellosi, and S. Guicciardi, "Processing and Properties of Zirconium Diboride-Based Composites," J. Eur. Ceram. Soc., 22, 279-88 (2002).

${ }^{15}$ F. Monteverde, S. Guicciardi, and A. Bellosi, "Advances in Microstructure and Mechanical Properties of Zirconium Diboride Based Ceramics," Mater. Sci. Eng., A346, 310-9 (2003).

${ }^{16} \mathrm{~F}$. Monteverde and A. Bellosi, "Oxidation of $\mathrm{ZrB}_{2}$-Based Ceramics in Dry Air," J. Electrochem. Soc., 150 [11] B552-9 (2003).

${ }^{17} \mathrm{~F}$. Monteverde and A. Bellosi, "The Resistance to Oxidation of $\mathrm{HfB}_{2}-\mathrm{SiC}$ Composite," J. Eur. Ceram. Soc., 25, 1025-31 (2005).

${ }^{18}$ F. Monteverde, "The Thermal Stability in Air of Hot Pressed Diboride Matrix Composites for Uses at Ultra-High Temperatures," Corrosion Sci., 47, 2020-33 (2005).

${ }^{19}$ L. Scatteia, R. Borelli, G. Marino, A. Bellosi, and F. Monteverde, "Characterization and Process of New Metal Diboride Compound for TPS Applications"; AIAA/CIRA 13th International Space Planes and Hypersonic Systems and Technology Proceedings. American Institute of Aeronautics and Astronautics, Reston, VA, 2005.

${ }^{20} \mathrm{~F}$. Monteverde and A. Bellosi, "Development and Characterization of MetalDiboride-Based Composites Toughened with Ultra-Fine SiC Particulates," Solid State Sci., 7 [5] 622-30 (2005).

${ }^{21}$ A. Chamberlain, W. Fahrenholtz, G. Hilmas, and D. Ellerby, "Oxidation of $\mathrm{ZrB}_{2}-\mathrm{SiC}$ Ceramics under Atmospheric and Reentry Conditions," Refractories Appl. Trans., 1 [2] 1-8 (2005).
${ }^{22}$ W. G. Fahrenholtz, "The $\mathrm{ZrB}_{2}$ Volatility Diagram," J. Am. Ceram. Soc., 88 [12] 3509-12 (2005).

${ }^{23}$ M. M. Opeka, I. G. Talmy, E. J. Wuchina, J. A. Zaykoski, and S. J. Causey, "Mechanical, Thermal, and Oxidation Properties of Refractory Hafnium and Zirconium Compounds," J. Eur. Ceram. Soc., 19, 2405-14 (1999).

${ }^{24}$ C. R. Wang, J. M. Yang, and W. Hoffmann, "Thermal Stability of Refractory Carbide/Boride Composites," Mater. Chem. Phys., 74, 272-81 (2002).

${ }^{25}$ M. Gasch, D. Ellerby, E. Irby, S. Beckman, M. Gusman, and S. Johnson, "Processing, Properties and Arc Jet Oxidation of Hafnium Diboride/Silicon Carbide Ultra High Temperature Ceramics," J. Mater. Sci., 39, 5925-37 (2004)

${ }^{26}$ I. Terrazas-Salinas and C. Cornelison, "Test Planning Guide for ASF Facilities"; A029-9701-XM3 Rev. B Thermophysics Facilities Branch, Space Technology Division, NASA Ames Research Center, CA, March, 1999.

${ }^{27}$ A. L. Cabrera and J. F. Kirner, "A Rapid-Temperature-Cycling Apparatus for Oxidation Testing," Oxidation Metals, 35 [5/6] 471-9 (1991).

${ }^{28}$ S. N. Karlsdottir, J. W. Halloran, F. Monteverde, and A. Bellosi, "Oxidation of ZrB2-SiC: Comparison of Furnace Heated Coupons and Self-Heated Ribbon Specimens (in press).

${ }^{29}$ N. S. Jacobson, "Corrosion of Silicon-Based Ceramics in Combustion Environments," J. Am. Ceram. Soc., 76 [1] 3-28 (1993).

${ }^{30}$ S. N. Karlsdottir, J. W. Halloran, and A. N. Grundy, "Zirconia Transport by Liquid Convection during Oxidation of Zirconium Diboride-Silicon Carbide," J. Am. Ceram. Soc., (in press; 2007). 